\title{
uPAR and HER2 Genes Are Usually Co-Amplified in Individual Breast Cancer Cells from Blood and Tissues
}

\author{
Jonathan Uhr \\ Cancer Immunobiology Center, UT Southwestern Medical Center, Dallas, USA
}

\section{Introduction}

We are interested in the distribution, at the individual tumour cell (TC) level, of two genes both associated with a poor prognosis in breast cancer. Using individual cell analysis, what is the correlation between overexpression and gene status of the above two genes and how do these results correlate with the pathologist's evaluation? Urokinase plasminogen activator ( $\mathrm{uPA}$ ) overexpression is associated with a poor prognosis in breast and other carcinomas. The uPA receptor (UPAR) is associated with uPA overexpression and, therefore, with increased tumour aggressiveness, worse disease-free survival and overall survival in breast and other cancers [1-9]. Very little is known about the regulation of uPAR expression. Its gene resides on the long arm of chromosome 19, encodes a protease of molecular mass 35 $\mathrm{kDa}$, and is linked to the outer surface of the plasma membrane by a glycosyl-phosphatidylinositol anchor. When uPAR interacts with one of its ligands, uPA, plasminogen is cleaved to active plasmin, which degrades several extracellular matrix (ECM) components and also activates many promatrix metalloproteases. As the ECM is the major physical obstacle for cancer cells to penetrate and invade the surrounding tissue, proteolytic degradation of the ECM facilitates migration and penetration through tissue boundaries, resulting in metastasis. In addition, other signalling pathways are activated to induce cellular proliferation, motility, and additional remodelling of the ECM. Therefore, it is important to develop new targeting drugs to inhibit the activation of uPAR by uPA or any other ligand [1-9].

The other gene, the HER 2 proto-oncogene, is amplified in $25 \%$ of invasive breast cancers, resulting in a decreased time of disease-free survival and other markers of poor prognosis. Trastuzumab (Herceptin $^{\circledR}$; Genentech, South San Francisco, CA, USA) is a HER2-directed humanised antibody that is effective for the treatment of patients with metastatic or early-stage breast cancer [10-12]. The methods used for selecting patients for trastuzumab therapy are immunohistochemical (IHC) analysis and gene-based fluorescent in situ hybridisation (FISH) analysis of primary tumours. Retrospective studies have shown that measurement of gene amplification is the best predictive marker of response to trastuzumab-based therapy [13-15].

Here, we have analysed the UPAR and HER2 gene status in individual TCs from touch preps (TPs) of primary breast carcinomas and also from circulating TCs (CTCs) in patients with advanced recurrent breast carcinoma. One objective was to determine whether the UPAR gene, like HER2, can be amplified. A second objective was to deter- mine the cellular distribution of the two amplified genes, e.g. whether they are amplified in separate TCs. Finally, we wanted to demonstrate the additional information that can be obtained from individual TC analysis.

\section{Patients and Methods}

\section{Patient Selection}

Women with a documented histological diagnosis of primary breast carcinoma or those with advanced metastatic breast carcinoma and normal agematched controls were recruited. All specimens were obtained with informed consent and collected using protocols approved by the Institutional Review Board at the University of Texas Southwestern Medical Center.

\section{Tissue Acquisition}

The University of Texas Southwestern Tissue Repository is a core facility that provided frozen breast cancer tissue from which we made TPs of primary cancers. Tumour tissue was washed for 2 min two times in $1 \leftrightarrow$-PBS and was cut into four sections. Each section was then touched gently onto a poly(L-lysine)-coated slide. Slides were air dried and fixed with $95 \%$ ethanol for $10 \mathrm{~min}$.

\section{Collection of Blood Samples}

Of blood, $30 \mathrm{ml}$ was drawn from the antecubital vein of patients into 10-ml Vacutainer tubes (BD Biosciences, San Diego, CA, USA), and CTCs were isolated as previously described using an immunomagnetic assay [16].

\section{Antibodies}

We used the following antibodies for direct staining: (i) fluorescein isothiocyanate (FITC)-labelled pan-anti-cytokeratin clone C11 (Sigma, St. Louis, MO, USA), (ii) anti-CD45 (clone 9.4 from American Type Culture Collection) conjugated in our laboratory to AlexaFluor 546 (Molecular Probes, Eugene, OR, USA), (iii) anti-HER81 mouse monoclonal antibody

\section{KARGER}

Fax +497614520714

Information@Karger.de

www.karger.com (c) 2008 S. Karger GmbH, Freiburg

Accessible online at:

www.karger.com/brc
Jonathan Uhr, M.D.

Cancer Immunobiology Center, UT Southwestern Medical Center 6000 Harry Hines Blvd

Dallas, Texas 750390-8576, USA

Tel. +1 214 648-1226, Fax -1252

jonathan.uhr@southwestern.edu 


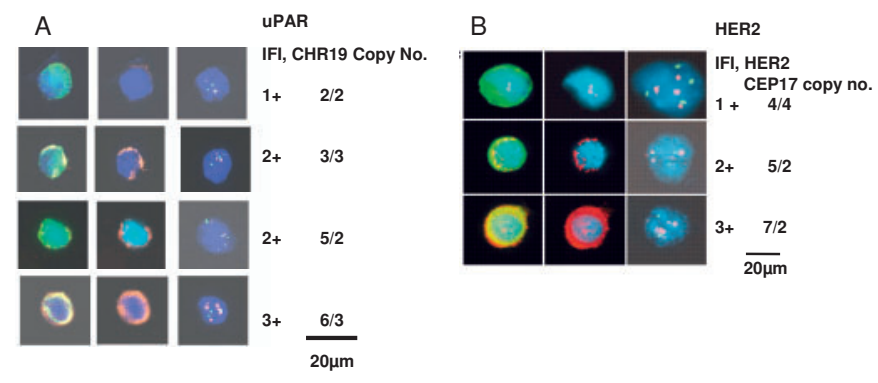

Fig. 1A. Left shows a typical single CTC. As can be seen, the nuclear to cytoplasmic ratio is high, the nucleus frequently has irregularities, and cytokeratin stains the cytoplasm at the periphery of the cell causing a ringlike appearance, all being accepted morphological and immunophenotypical criteria for malignant cells. Center shows uPAR expression by IF in the same CTC. Right shows the results of FISH analysis. The signals can be precisely read on individual CTCs. It is relatively straight-forward to subjectively quantify individual TCs or CTCs into 1-3+ expression as determined above. 1B. shows HER2 gene amplification and expression in representative CTCs, similar to fig. 1A [19].

(E. Vitetta) conjugated to AlexaFluor 594, and (iv) anti-uPAR mouse monoclonal antibody, clone 62022 (R\&D Systems, Minneapolis, MN, USA) conjugated in our laboratory to AlexaFluor 546.

\section{Immunofluorescence Staining and Detection of CTCs}

The detection of epithelial cells is accomplished by immunofluorescence (IF) using anti-CK and anti-CD45, as previously described [16].

Slides were examined manually for the presence of epithelial cells using a fluorescent microscope (Axiophot; Zeiss, Jena, Germany). Scanning for CK- and CD45-positive cells was performed with a single bandpass filter for FITC and AlexaFluor 546. To assure that the FITC staining was associated with the correct cell, the same area was evaluated with a dual bandpass filter for FITC-DAPI (DAPI: 4,6-diamidino-2-phenylindole dihydrochloride). The location of each TC on the slide was recorded and stored. An image from each positive cell was acquired to confirm that the same cell was relocated when performing multicolour FISH.

\section{Multicolour FISH}

Hybridisation and post-hybridisation procedures were performed according to the manufacturer's instructions (Abbott Molecular, Des Plaines, IL, USA). HER2 FISH was analysed first, and then the TC was reprobed for uPAR. After hybridisation, the cell image from automated relocation and the previously recorded image were visually compared to confirm relocation accuracy. The FISH signals of TCs were evaluated by using specific filters for each fluorochrome. One probe set contained a FISH probe hybridising to a region including the HER2 gene and a probe controlling for chromosome 17 aneusomy (Path-Vysion; Abbott Molecular). The second probe set contained a probe hybridising to a region including the UPAR gene labelled with Spectrum-Orange, and a control probe for measuring chromosome 19 aneusomy labelled with Spectrum-Green. For each relocated cell, an image was recorded to document the results of FISH. The leukocytes on the patients' slides were used as control cells for the hybridisation quality. Gene amplification within a cell was defined as either 2 HER2 signals per chromosome 17 signals, or 2 uPAR signals per chromosome 19 signals.

\section{Results}

\section{Characteristics of Individual TCs}

Isolated epithelial cells in our slide-based assay can be unambiguously characterised as TCs because of their distinctive immunophenotype, cytomorphology, and, most importantly, the presence of aneusomy [16-18] (fig. 1A, B).

\section{Distribution of HER2 and UPAR Gene Status in Individual TCs of HER2+ Patients}

The gene status of individual cells of primary tumours and CTCs was divided into 4 subsets: both genes amplified, only one of the genes amplified, or neither amplified.

The results of gene amplifications for TCs from 12 HER2 primary tumours (100 TCs per patient) and CTCs from 2 HER2 patients (50 and 100 CTCs per patient) are shown in table 1.

As can be seen, there is a marked preference for amplification of both HER2 and uPAR genes to occur in the same TC rather than in separate TCs in HER2-amplified primary tumours, as well as in CTCs from 2 patients with advanced disease. Using linear regression models, both the HER2 copy number ability to predict UPAR copy number and the HER2 ratio predicting UPAR ratio also gave highly significant $\mathrm{p}$-values for each patient. The patients described in table 1 all had a sufficient number of HER2-amplified TCs to allow statistical analysis of gene status.

Patients with HER2-negative primary tumours (16 patients) or CTCs (24 patients) did not have a sufficient number of HER2- or uPAR-amplified TCs to perform meaningful analysis. Thirteen HER2-amplified cases with CTCs did not have sufficient numbers of CTCs for statistical analysis except for the 2 patients in table 1 . However, there was the same preference for co-amplification as shown in table 1 in virtually every patient.

\section{Correlation of HER2 and UPAR Gene Status between TPs and Primary Tumours}

For individual TC analysis of tumour tissue, it is necessary to determine whether the gene status from TPs is concordant with conventional pathological analysis.

The results of HER2 gene status using TPs (100 TCs per patient) compared with the pathologist's analysis showed concordance in all 21 patients $(100 \%$ concordance, with $95 \%$ confidence interval (CI) of 84-100\%). Moreover, the ratios using TP and conventional pathological analysis were very close in each patient. uPAR gene status using TPs compared with the pathologist's analysis were also concordant in all 7 patients (100\% concordance with $95 \%$ CI of 59-100\%). More patients are required to determine uPAR correlations and how to calculate the uPAR gene status. Nevertheless, it appears that TPs can be used to determine the HER2 and, potentially, the UPAR gene status in patients. In HER2-amplified cases using TPs and CTCs, 92\% (23 of 25) were also uPAR gene amplified, whereas in HER2-non-amplified patients, only $3 \%$ (1 of 39 ) were uPAR gene amplified.

\section{Correlation of HER2 Gene Status between CTCs and Primary Tumour}

The HER2 gene status of CTCs in 52 patients with recurrent or progressive advanced breast cancer was compared with the pathologist's 
Table 1. Distribution of HER2 and uPAR gene amplification in individual TCs of HER2+ patients

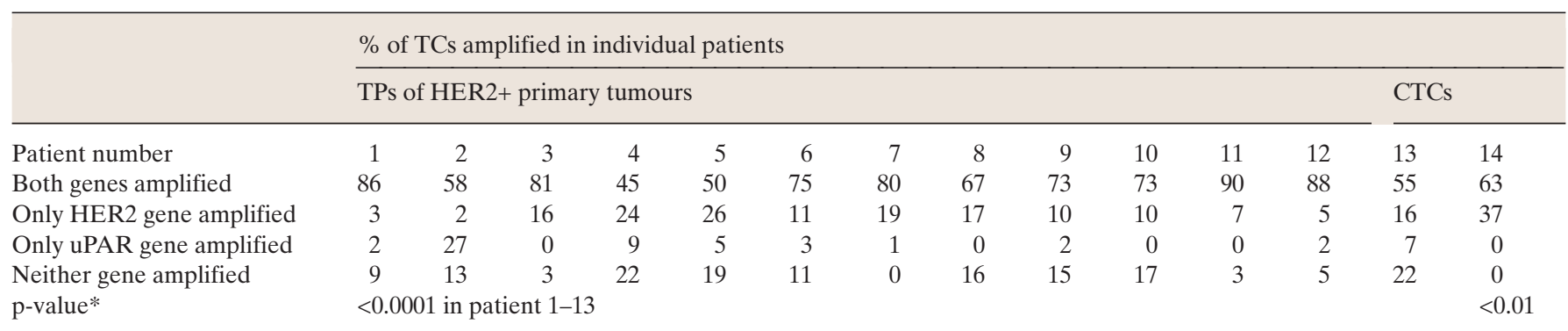

*Exact binomial test was used to compare TCs with both genes amplified to those with only one gene amplified. 100 TCs were analyzed in each patient except \#14 which had 50 CTCs. Percentages were rounded for simplicity.

analysis of the HER2 gene status of their primary tumour. Their patterns of HER2 distribution were similar to those whose primary tumour was HER2-negative if acquisition of HER2 gene amplification (5 patients) was considered.

\section{Correlation of Expression of HER2 and UPAR with Gene Status in Primary Tumours and CTCs}

Twenty-seven TPs (100 TCs per patient) from primary tumours showed a concordance of $100 \%$ (95\% CI, of $89-100 \%$ ) between expression and gene status of HER2 ( $\mathrm{p}<0.001$ using exact binomial test). For uPAR, the concordance was $96 \%$ (95\% CI, 83-100\%) if the copy number of chromosome 19 was subtracted from the copy number of uPAR ( $p<0.001$ using exact binomial test). With regard to CTCs, 10 patients (193 CTCs) exhibited HER2 amplification; 36 patients (670 CTCs) were non-amplified.

There was a concordance in 44 of 46 patients between HER2 expression and gene status in the CTCs $(96 \%$ concordance, $95 \%$ CI, 86-99\%). For uPAR, the concordance was $92 \%$ (95\% CI, $65-100 \%$, 11 of 12 patients; $\mathrm{p}<0.02$ using exact binomial test). The results suggest a significance of UPAR amplification associated with uPAR expression. Therefore, correlation between protein expression and gene status for HER2 and UPAR in patients is very high.

\section{Discussion}

The major conclusions from the present study of individual TCs are: (i) Individual TC analysis can provide additional information not available from conventional pathological analysis, i.e. multigene analysis of single TCs, subdividing a population of TCs into subsets that each display a particular genetic change and allowing more precise predictability of gene amplification from gene expression. (ii) uPAR gene amplification is described in $20-25 \%$ of primary breast cancers. To our knowledge, this is the first report of such amplification in any cancer.

Conventional pathological analysis and TP assays showed complete concordance with HER2 and UPAR gene status in 21 and 7 consecutive patients, respectively, thereby validating the use of TPs for this purpose $(\mathrm{p}=0.0001)$. Similar results were obtained with HER2 gene status of CTCs and pathological analysis of primary tumours, provided acquisition of HER2 gene amplification in CTCs associated with cancer progression was taken into consideration [20].

Expression of HER2 protein in 52 cases using either their primary tumours or CTCs showed a minimum of $96 \%$ concordance with HER2 gene amplification determined by the pathologist.

Analysis of uPAR and HER2 gene status in TPs of primary breast carcinomas and CTCs of patients with advanced breast carcinomas revealed a marked bias for amplification of both oncogenes in the same TC. The higher the HER2 ratio, the more likely it was to have co-amplification and to have higher levels of UPAR amplification. The likelihood of HER2 and uPAR gene overexpression occurring in the same primary breast cancer by conventional pathological analysis has been reported [21] and is consistent with co-amplification. Co-amplification suggests crosstalk and cooperativity between the HER2 and uPAR signalling pathways. The possible clinical implications of coamplification on the responsiveness of HER2+ patients to trastuzumab require further study.

\section{Acknowledgements}

This work was supported by National Cancer Institute Grant CA 10179001A3 and the Susan B. Komen Foundation Grant BCTR0504014.

\section{References}

1 Sidenius N, Blasi F: The urokinase plasminogen activator system in cancer: Recent advances and implication for prognosis and therapy. Cancer Metastasis 2003;22:205-222.

2 Romer J, Nielsen BS, Ploug M: The urokinase receptor as a potential target in cancer therapy. Curr Pharm Des 2004;10:2359-2376.

$\checkmark 3$ Grondahl-Hansen J, Peters HA, van Putten WL, Pappot H, Ronne E, Dano K, Klijn JG, Foekens JA: Prognostic significance of the receptor for urokinase plasminogen activator in breast cancer. Clin Cancer Res 1995;1:1079-1087.
4 de Witte JH, Foekens JA, Brunner N, Heuvel JJ, van Tienoven T: Prognostic impact of urokinasetype plasminogen activator receptor (UPAR) in cytosols and pellet extracts derived from primary breast tumours. Br J Cancer 2001;85:85-92.

$\checkmark 5$ Hemsen A, Riethdorf L, Brunner N, Berger J, Ebel S, Thomssen C, Janicke F, Pantel K: Comparative evaluation of urokinase-type plasminogen activator receptor expression in primary breast carcinomas and on metastatic tumour cells. Int J Cancer 2003; 107:903-909.
6 Riisbro R, Christensen IJ, Piironen T, Greenall M, Larsen B, Stephens RW, Han C: Prognostic significance of soluble urokinase plasminogen activator receptor in serum and cytosol of tumour tissue from patients with primary breast cancer. Clin Cancer Res 2002;8:1132-1141.

7 Duggan C, Maquire T, McDermott E, O’Higgins N, Fennelly JJ, Duffy MJ: Urokinase plasminogen activator and urokinase plasminogen activator receptor in breast cancer. Int J Cancer 1995;61:597-600. 
8 Kotzsch M, Farthmann J, Meye A, Fuessel S, Baret ton G, Tjan-Heijnen VC: Prognostic relevance of uPAR-del4/5 and TIMP-3 mRNA expression levels in breast cancer. Eur J Cancer 2005;41:2760-2768.

$\checkmark 9$ Werle B, Kotzsch M, Lah TT, Kos J, GabrijelcicGeiger D: Cathepsin B, plasminogenactivator-inhibitor (PAI-1) and plasminogenactivator-receptor (uPAR) are prognostic factors for patients with non-small cell lung cancer. Anticancer Res 2004;24: 4147-4161.

10 Slamon DJ, Leyland-Jones B, Shak S, Fuchs H, Paton V, Bajamonde A, Fleming T, Eiermann W, Wolter J, Pegram M, Baselga J, Norton L: Use of chemotherapy plus a monoclonal antibody against HER2 for metastatic breast cancer that overexpresses HER2. N Engl J Med 2001;344:783-792.

11 Romond EH, Perez EA, Bryant J, Suman VJ, Geyer CE Jr, Davidson NE, Tan-Chiu E, Martino S, Paik S, Kaufman PA, Swain SM, Pisansky TM, Fehrenbacher L, Kutteh LA, Vogel VG, Visscher DW, Yothers G, Jenkins RB, Brown AM, Dakhil SR, Mamounas EP, Lingle WL, Klein PM, Ingle JN Wolmark N: Trastuzumab plus adjuvant chemotherapy for operable HER2-positive breast cancer N Engl J Med 2005;353:1673-1684.
12 Piccart-Gebhart MJ, Procter M, Leyland-Jones B, Goldhirsch A, Untch M, Smith I, Gianni L, Baselga J, Bell R, Jackisch C, Cameron D, Dowsett M, Barrios $\mathrm{CH}$, Steger G, Huang CS, Andersson M, Inbar M, Lichinitser M, Láng I, Nitz U, Iwata $H$, Thomssen C, Lohrisch C, Suter TM, Rüschoff J, Suto T, Greatorex V, Ward C, Straehle C, McFadden E, Dolci MS, Gelber RD: Trastuzumab after adjuvant chemotherapy in HER2-positive breast cancer. N Engl J Med 2005;353:1659-1672.

13 Yeon $\mathrm{CH}$, Pegram MD: Anti-erbB-2 antibody trastuzumab in the treatment of HER2-amplified breast cancer. Invest New Drugs 2005;23:391-409.

14 Ross JS, Fletcher JA, Bloom KJ, Linette GP, Stec J, Summans WF, Pusztai L, Hortobagyi GN: Targeted therapy in breast cancer: The HER2/neu gene and protein. Mol Cell Proteomics 2004;3:379-398.

15 Slamon DJ, Clark GM, Wong SG, Levin WJ, Ullrich A, McGuire WL: Human breast cancer: correlation of relapse and survival with amplification of the HER2/neu oncogene. Science 1987;235:177-182.

16 Meng S, Tripathy D, Frenkel EP, Shete S, Naftalis EZ, Huth JF, Beitsch PD, Leitch M, Hoover S, Euhus D, Haley B, Morrison L, Fleming TP, Herlyn D, Terstappen L, Fehm T, Tucker TF, Lane N, Wang J, Uhr J: Circulating tumour cells in patients with breast cancer dormancy. Clin Cancer Res 2004;10: $8152-8162$.
17 Fehm T, Morrison L, Saboorian H, Hynan L, Tucker T, Uhr J: Patterns of aneusomy for three chromosomes in individual cells from breast cancer tumours. Breast Cancer Res Treat 2002;75:227-239.

18 Fehm T, Sagalowsky AI, Clifford E, Beitsch PD, Saboorian H, Euhus D, Meng S, Morrison L, Tucker T, Lane N, Ghadimi BM, Heselmeyer-Haddad K, Ried T, Rao C, Uhr J: Cytogenetic evidence that circulating epithelial cells in patients with carcinoma are malignant. Clin Cancer Res 2002;8: 2073-2084.

19 Meng S, Tripathy D, Shete S, Ashfaq R, Saboorian H, Haley B, Frankel E, Euhus D, Leitch M, Osborne C, Clifford E, Perkins S, Beitsch P, Khan A, Morrison L, Herlyn D, Terstappen L, Lane N, Wang J, Uhr J: uPAR and HER2 gene status in individual breast cancer cells from blood and tissues. Proc Natl Acad Sci USA 2006;103:17361-17365.

20 Meng S, Tripathy D, Shete S, Ashfaq R, Haley B, Perkins S, Beitsch P, Khan A, Euhus D, Osborne C, Frenkel E, Hoover S, Leitch M, Clifford E, Vitetta E, Morrison L, Herlyn D, Terstappen L, Fleming T, Fehm T, Tucker T, Lane N, Wang J, Uhr J: HER2 gene amplification can be acquired as breast cancer progresses. Proc Natl Acad Sci USA 2004;101: 9393-9398.

21 Han B, Nakamura M, Mori I, Nakamura Y, Kakuda $\mathrm{K}$ : Urokinase-type plasminogen activator system and breast cancer (review). Oncol Rep 2005;14: 105-112. 